Bond University

Research Repository

\title{
Dynamic interactive learning systems
}

Sabry, Khaled; Barker, Jeff

Published in:

Innovations in Education and Teaching International

DOI:

$10.1080 / 14703290902843836$

Licence:

Other

Link to output in Bond University research repository.

Recommended citation(APA):

Sabry, K., \& Barker, J. (2009). Dynamic interactive learning systems. Innovations in Education and Teaching International, 46(2), 185-197. https://doi.org/10.1080/14703290902843836

\section{General rights}

Copyright and moral rights for the publications made accessible in the public portal are retained by the authors and/or other copyright owners and it is a condition of accessing publications that users recognise and abide by the legal requirements associated with these rights.

For more information, or if you believe that this document breaches copyright, please contact the Bond University research repository coordinator. 


\title{
Dynamic Interactive Learning Systems
}

\author{
Khaled Sabry ${ }^{1}$ and Jeff Barker ${ }^{2}$ \\ ${ }^{1}$ Al-Ain University, Al-Ain, UAE; 2 Bond University, Queensland, Australia
}

\section{SUMMARY}

This paper reviews and discusses the notions of interactivity and dynamicity of learning systems in relation to information technologies and design principles that can contribute to interactive and dynamic learning. It explores the concept of dynamic interactive learning systems based on the emerging generation of information as part of a continuous research in the area of Learning Systems Design. It proposes the addition of a Dynamicity dimension to interactive learning systems' design to reflect the continuous changes in information technologies, learners' needs and increasing availability of information. The paper concludes with a proposed model that reflects the concept of a dynamic feedback and adjustment mechanism that is generally missing from many learning systems.

\section{INTRODUCTION}

Perhaps one of the most ongoing and complex questions in education is how educational organisations can deal simultaneously with multiple types of learner without ignoring their differences. Many universities and colleges have students with considerable differences in age, past experience, gender, culture, language, level of attendance, ability and needs. Learners may also have different learning styles and preferences that may be distinct from those planned by educators. Adding to the complexity are many technological changes and the new era of information related to Information and Communication Technology (ICT). Further, many students have limited time available for studying due to work or other social responsibilities, while most time spent travelling to/from university/college/school and on campus is related to physical attendance rather than the actual learning process. It is 
important for students to learn how to learn, how to be an independent learner and how to communicate with others to find relevant information. Through the use of ICT, learning costs and time may be reduced through the reduction of physical attendance and its consequences. This is not to eliminate entirely face-to-face interaction but to minimize it through complementing it with technology. How can such differences be accommodated while providing dynamic, enjoyable and interactive learning? While different education experts will provide different answers, consequent knowledge will emerge to help guide design decisions for relevant, effective and efficient learning systems. An essential step will be undoubtedly be better understanding of the advances in information technologies as well as learners' increasingly changing needs.

As we have progressed to the information era, the amount of information has become greater, access is much faster, the information has become global, the information is more accessible, different search parameters can be used, dynamic information is replacing static information and ICT increasingly provides the 'electronic nervous system' for many organizations through the increasing use of mobile technologies such as 'smart' phones, data-capture technologies such as Radio Frequency Identification (RFID) and Internet usage. According to recent statistics, the world usage of the Internet increased approx 245\% between 2000 and 2007 (IWS, 2007). Statistics show that the number of Internet devices reached 600 million in 2006 compared with 1 million in 1992. Many of today's college majors did not exist 10 years ago (eg new media, e-business, nanotechnology, etc); the amount of technical information is doubling every 2 years and in 2010 is predicted to double every 72 hours; and $3^{\text {rd }}$ generation fiber optics have recently been tested that push 10 trillion bits per second down a fiber (equal to approx 1,900 CDs or 150 million simultaneous phone calls every second), meaning that marginal cost of those improvements is effectively zero (Glumbert, 2008). Further, increasingly accessing the Internet for information is on the increase (ONS, 2007). However, currently, a large gap exists between the information available and the use of that information (Barker, 2005; 
Barker, 2007; Barker and Finnie, 2004). Most current systems (in government, law, finance, economics, business, management, manufacturing, etc) were designed in the old information generation, the pre-dynamic information generation (DIG), and most decision makers were brought up and made decisions based on the old generation, not DIG. Very few systems have been designed for DIG. This means more than just applying DIG techniques to systems built or developed in the pre-dynamic information era. Information is of paramount importance for decision making; for example, sensible decisions cannot be made without information or made with old out-of-date information. An invaluable feedback mechanism for each student, for each class, for each year, for each school, for each province, for each state and finally at national level, will enable rapid comparisons between national results and the national syllabi. Currently, this generally takes a long time, at least 12 months. Using dynamic feedback, this time will be cut back to possibly days. The most up-to-date information (dynamic information), typically provided by an information system, must be used.

\section{INTERACTIVITY OF LEARNING SYSTEMS}

Designing an effective learning system requires looking at several variables and considerations; including interactivity and interaction design (Graham et al., 2000). For a learning system to be interactive for different types of learner, it will be necessary to take account of the users (the learners) who are expected to use such systems for learning, and it is not merely enough to give students access to different tools and/or learning environments (Bates and Leary, 2001). It requires a move from a teacher-student dependence design to a teacher-student independence design that gives students flexibility and control over their learning in line with their changing needs. This essentially requires investigation of factors such as learners' different learning preferences, needs, interests, prior knowledge, experiences, background, culture, talents and abilities. Further, the focus should be on the best available knowledge about learning, how it occurs and the effective 
ways for achieving it for the learners. Learner-centred pedagogy should be based on learners' needs rather than teachers' or institutions' needs and should be compatible with the use of information and communication technology especially those that promote the teachers as a facilitators (Tam, 2000).

Interactivity is at the heart of learning systems design for the influential role it plays in the effectiveness of the learning process (Moore and Kearsley, 1996) and as a fundamental mechanism for knowledge acquisition (Barker, 1994). Using an interactive web-based learning program can increase the learning enjoyment level, which in turn may increase students' understanding and the effectiveness of learning in a longer timeframe in terms of information retention (Street and Goodman, 1998). Some authors have argued that interactivity of Computer Mediated Learning (CML) can boost the speed and level of student learning (Horton, 2000; Najjar, 1998) and helps to improve students' confidence and motivation (Klassen et al., 2001).

There have been several attempts to define the interactivity of computer/web-based systems (Laurillard, 2002; Graham et al., 2000) that support a learner-centred design. Interactivity of learning systems can be claimed to have certain features or mechanisms that allow students to act to achieve certain tasks, receive relevant intrinsic feedback on their actions and a change occurs as a result of their reactions (Laurillard, 1993). According to Reeves (1999), a learning environment can be described as interactive when it allows a person to perform meaningful activities such as navigating through it, selecting information, responding to questions using computer input devices such as a keyboard, mouse, touch screen, or voice command system, solving problems, completing challenging tasks, creating knowledge representations, collaborating with others, or otherwise engaging in meaningful learning activities. Interactivity of learning systems can take different shapes through using different types of learning interaction, which can be categorised into three main types: learner-content where a learner interacts with information, learner-instructor 
where the learner interacts with experts, and learner-learner where the learner interacts with other learners (Moore, 1989; Moore and Kearsley, 1996). Evans et al (2002) combined a set of principles (heuristics) for interactive systems, which includes not only appropriate use of multimedia and active engagement of the learner, but also allowing for reflection which can help learners in filling the gaps in their own understanding (Lin et al., 1999).

Interactive Learning Systems (ILS) therefore, adopt some design principles such as active learner's engagement (Alexander and Boud, 2001), active thinking (Salmon, 2002), engagement of the learner with a variety of interactions with materials, peers, and experts (Bonk, 1999; Park, 2003), flexibility in expanding interactions beyond the lecture or tutorial in case of campus based learning (Jung et al., 1998), allow for reflection and provide feedback (Laurillard, 2002), provide choices, easy navigation, variety of interaction patterns, and use of multimedia (Evans et al., 2002), including graphics, which may promote discovery and inference (Mayer, 1989; Tessler et al., 1995). Interactivity of learning systems also take into account actual learners' profile including for example, LSs, their use and perceptions of usefulness of different types of CMLI, individual differences, and learning preferences in relation to traditional methods (Sabry, 2005; Sabry and AlShawi, 2008).

\section{COMPONENTS OF AN ITERACTIVE LEARNING SYSTEM (ILS)}

A learning system generally consists of four main components (Sabry, 2005). The Learner component is concerned with knowledge about the learner such as individual differences (for example, gender, prior knowledge, age, culture and special needs); learning styles (for example, Sequential/Global, Active/Reflective and Visual/Verbal); performance and attainment level; attitudes and beliefs. The Subject Content component, includes information that constitutes relevant subject knowledge required to be learned including 
internal information or actual contents provided (subject material) and other external information that are relevant or supplementary to subject material, for example, searching the Internet for information such as papers relevant to subject material), items to be taught, course aims and objectives, and skills to be developed (Figure 1).

Figure 1 about here

The Technology component is concerned with how a course of study may be delivered in terms of different tools to be used, including usability, interactivity, navigation, and human-computer interaction (HCI ) aspects of learning systems. It also includes hardware issues, for example whether fixed position (PCs) or mobile (Laptops and PDAs). The technology component is an important part of the learning system, but should not be treated as a determiner of the system design or treated in isolation of the other components. It includes knowledge about the media through which information can be delivered, for example, e-mail, Internet search engines, learning environments such as FirstClass, WebCT and Blackboard, where different types of learning interaction can be accommodated, including different combinations of multimedia representations to accommodate different types of interaction, teaching and learning styles. Learning environments generally include four main components, an enabling context, resources, tools, and scaffolds (Hannafin et al., 1999) and more specifically, Personal Learning Environments (PLE) transfer the management of learning from the institution to the learner (BECTA, 2007). On the other hand, multimedia learning technologies can provide different combinations of picture (static and/or dynamic) and word (written or spoken) (Mayer, 2001; Najjar, 1998).

Whilst this study views technology as a tool and a black box, it does not underestimate the importance of the understanding of ICT artifacts, as part of the Technology component of 
an ILS, in order to cope with ongoing changes (Orlikowski and Iacono, 2001) and support the adaptation notion of learning systems. However this should be in conjunction with, not on the account of, the Learner component and/or other components of an ILS. The instructional design should not only be concerned with delivering information to learners, but also with the efficient way information is presented (Mayer, 2001), the way learning interactions can be designed to engage learners, and the way student-assessment can be implemented. Further, the design and development of relevant and appropriate electronic sharing mechanisms is essential to achieve flexibility of access and delivery of educational materials in a global manner (Barker, 1997).

The Pedagogy component is concerned with how a course of study will be delivered in instructional terms. This may include for example, information about different learning theories (instructivism, cognitivism, and constructivism), instructional approaches (for example learner-centred), methods and styles of teaching relevant to the subject matter (such as problem solving, deep, surface, etc) and to different learning styles and strategies, learning interactions, contexts and models of learning. Interactivity of learning systems can take different shapes through using different types of learning interaction, which can be categorised into three main types: Student-Content where learner interacts with information, Student-Lecturer where the learner interact with experts, and Student-Student where the learner interacts with other learners (Moore 1989; Moore and Kearsley, 1996). These three categories of interaction (Figure 2) can play an important role in making the learning process an interactive one, by helping to adapt instructions to better suit learners' requirements (Jonassen, 1988), expanding interaction beyond the lecture or tutorial (Jung et al, 1998), encouraging learners to actively process information (Bower and Winzenz 1970), providing access to learning resources (Jung and Leeme, 1999), adding flexibility to learning (Naidu, 1997; Reeves and Reeves, 1997), and allowing learners to interact synchronously and asynchronously in collaborative and distributed environments (Harasim et al., 1995). 
Figure 2 about here

ICT is at the heart of CML. Education that is supported by ICT can promote the acquisition of the knowledge and skills that will empower students for lifelong learning, if designed and implemented properly (World Bank, 1998). According to research, appropriate use of ICT can catalyze the paradigmatic shift in both content and pedagogy that is at the heart of educational reform (Bransford, 1999). However, the availability of learning interactions tools in learning environments is not solely considered sufficient, the incorporation of such interactions into the learning design is essential for the effectiveness of both the flow of interaction and learning (Nelson, 1999).

\section{INTERACTIVE LEARNING SYSTEM (ILS) MODEL}

The degree of a system's interactivity will depend on how the learning system's components are coordinated and managed. The Interaction component (Figure 3) will help in coordinating and balancing the other four elements, for example, how the learner interacts with the computer system, the design of the interface between these, presentation of multimedia considerations and decisions about interactivity level, interaction, and consideration of the teaching styles to be used according to skills to be developed as well as learners' needs.

Figure 3 about here 


\section{ADDING THE DYNAMICITY DIMENSION TO THE ILS MODEL}

Dynamic information can be defined as information that is updated instantly as soon as changes occur and is available to those who need it at the time and in the form and relevance in which it is needed (Barker, 2007; Barker and Finnie, 2004). Many learning systems have been designed without much attention to the next generation of information, Dynamic Information Generation (DIG). There are two perspectives for the relationship between the DIG and education: educate for the DIG and educate in DIG. Educating for DIG will be required at all levels of education, from primary to university. This will include developing skills and literacy in digital age literacy [informational, technological, cultural, global, functional and scientific literacy], inventive thinking [adaptability, curiosity, creativity and risk taking], higher order thinking [creative problem solving and logical thinking], and effective communication [collaboration, interpersonal skills, team work, personal and social responsibility, interactive communication and high productivity] (EnGuage, 2004).

On the other hand, for education in DIG, ICT greatly facilitates the acquisition and absorption of knowledge, offering unprecedented opportunities to enhance educational systems all over the world, reducing any sense of isolation, and opening access to knowledge in different ways (Blurton, 1999). Education in DIG is therefore for all (classical or modern, formal and non-formal, urban and non-urban, ethnic minorities, special needs, male or female, young or elderly) at any location anytime with a more flexible pedagogy. It seeks more variations of different activities, collaboration, creativity (Figure 4), integration (between theory and practice and between different subjects and disciplines) and evaluative learning (towards a more diagnostic approach rather than summative and student directed rather than teacher-directed) from teacher-focused to learner focused (Thijs et al., 2001). Moving education to DIG requires changes to: the role of teachers, education process and progress (non-median), customization of text books from static to dynamic, redefining the conduct of class teaching, and distance education. 
Figure 4 about here

This paper proposes adding the Dynamicity Component to the ILS design (Figure 3) to develop a Dynamic Interactive Learning System (DILS), which can be defined as an ILS that implements DIG principles (Figure 5). DILS will not only have interactive components, but dynamic components rather than static, components that are constantly updated and modified based on latest research and updated knowledge gained in the field concerned. It is based on open systems that are flexible, adaptable, adaptive, interactive, relevant, anytime and anywhere similar to the Living System paradigm and the Gardening analogy described by Ray Paul (1993). The DILS advocates the inclusion of a dynamic feedback and adjustment mechanism which is largely ignored by most learning systems. Based on the proposed DILS model, students are assessed on a regular basis, with the marking being done electronically for appropriate subjects and the individual dynamic text books, workbooks and exercises being constructed according to the assessment, focusing on students' knowledge. The dynamic texts will typically be only about one to two weeks ahead of the student. They will NOT be created for a year or even a term. They will be consistently built on the individual student's knowledge of the topics at that time. The DILS also stresses and highlights the importance of the balancing concept through the interaction and coordination between the different components of the model based on upto-date and dynamic information including course material, relevant technology, pedagogy and learners' actual profile in order to both accommodate students' differences and develop skills required in a relevant and balanced manner.

Figure 5 about here 
Course Material (content): this component should contain up-to-date links to up-to-date information and knowledge resources related to subject area in digital form (eg e-book, virtual lecture, e-libraries, web, simulations, labs, etc). It should not be tied to a hard copy of a text book or static means of information or knowledge, but dynamic digital information and knowledge that are constantly updated and modified based on the amount of knowledge absorbed by the learner. Such Information is not tied to a particular place or time. E-books are no longer static, but interactive and updated by their authors where and when applicable. It contains tasks to be taught in relation to course aims and objectives, learner profile and skills to be developed. This should also contain links to recent research in the subject area as well as dictionaries to support students from different parts of the world. As an example, each student in a class will have his/her own dynamic text book, the content of which is based on the constantly updated (dynamic) evaluation of the student's knowledge and understanding of the material.

Learner: this component contains actual and dynamic information including up-to-date information about level of attainment, courses evaluation results (as it occurs), efforts, progress, and considerations about the student, including individual differences (eg gender, culture, prior knowledge, language, age, etc.) and preferred learning styles (eg sequential, global, Active, etc.).

Educational Technology: contains up-to-date knowledge and considerations about the media through which course contents can be delivered and multimedia representation to accommodate different types of interaction, teaching and learning styles. This also includes different technologies whether asynchronous and/or synchronous. This component is a dynamic component that seeks up-to-date technologies and use of a variety of innovative technologies to accomplish the system's goals and objectives, for example, the use of latest technologies that assist the flexibility, adaptivity, adaptability and learning interactivity available anytime, anywhere without geographical, special or temporal limitations, such as: 
- GIS (Geographical Information Systems) and mapping technologies for capturing, storing, analyzing and managing spatial and associated data

- Radio Frequency Identification (RFID) for data capture and education exploration

- Global Positioning Systems

- Smart phones, PDA, Wi-Fi, Nano, etc.

It may include software agents that exhibit some form of artificial intelligence or some sort of embedded intrinsic and seamless actions that assists the users and act on their behalf, in performing repetitive computer-related tasks, for example:

- learn and improve through interaction with the environment (embodiment)

- adapt online and in real time

- learn quickly from large amounts of data

- accommodate new problem solving rules incrementally

- memory-based exemplar storage and retrieval capacities

- parameters to represent short and long term memory, age, forgetting, etc.

- ability to analyze itself in terms of behaviour, error and success

- perform diagnostic evaluation of student progress to assist learning improvement and provide feedback for student evaluation.

Pedagogy: this component contains pedagogical knowledge that is dynamic and constantly updated with methods and styles of teaching relevant to each subject matter, aims and objectives, relevant to DIG and learners' differences. The wider the range of different strategies, the more effective and efficient the teaching and learning will be. This component should include assessment strategies that are compatible with DIG, i.e. student evaluation methods should not be tied to temporal or spatial constraints, but should use 
evaluation methods that are more diagnostic, based on dynamic information relating to the student progress, achievements and pace.

Learning Interaction Design: this is the component that coordinates and balances the other four components, based on up-to-date and dynamic course material, technology, pedagogy and learners' profile. It also helps to produce learning systems taking into account HCI design principles, multimedia presentation considerations and decisions about interactivity level, type of interactions, and teaching styles to be used in accordance to different contents, different learners and technologies used. It is constantly updated with knowledge of best interaction practices. DILS engages the learner with a variety of interactions with materials, peers, and experts and allows not only for the 3 types of learning interaction of ILS, but also for Lecturer-Information interaction (where lecturers have access to latest and up-to-date information available) and Lecturer-Lecturer Interactions (where knowledge can be shared between lecturers and/or experts). These interactions are incorporated through the 'Interaction' component of the DILS. Figure 6 shows the five types of interaction incorporated in DILS.

Figure 6 about here

\section{CONCLUSIONS AND FUTURE WORK}

Education programmes and learning systems must be designed for the increasingly different mix and combination of learners with considerable age differences, backgrounds, abilities, culture, gender, past experience, different needs, full and part-time, as well as learning styles and communication preferences. Equally important, they need to adequately prepare students for this new volatile, continuously changing and dynamic era the world is now moving into. The current systems and programmes were designed in and for the pre- 
dynamic information era. The world has moved into the Dynamic Information Generation (DIG); education must also move into DIG to be more effective, relevant and compatible with continuous changes in industry and advances in information technologies. An effective DILS design, takes into account different learners and their changing needs, technological advances to accommodate different needs, different and suitable methods of teaching/learning to accommodate students' different needs and develop required skills. The Interactivity and Dynamicity dimensions are vital to provide a dynamic feedback and adjustment mechanism to cope with continuous changes in information, communication, technology, business and learner's needs.

The review outlined in this paper as well as the proposed DILS model are only attempts towards more understanding of our new era of ICT and is hoped to lead to improvements in the design of learning systems towards a more dynamic and interactive participation by high percentage of students that in turn should lead to important gains in the acceptability and usefulness of such systems as the awareness of the pedagogical implications related to the use of dynamicity and interactivity dimensions can lead to more effective and usable learning systems. Further, research is needed to examine different applications of the DILS model and different learning interactions that best support students globally.

\section{REFERENCES}

Alexander, S. and Boud, D. (2001) Learners still learn from experience when online. In Stephenson, J. (ed) Teaching and Learning Online: Pedagogies for New Technologies, Kogan Page, London, UK.

Bates, B. and Leary, J. (2001) Supporting a range of learning styles using a taxonomybased design framework approach. ASCILITE 2001 Conference Proceedings, December 912, Melbourne, pp45-53.

Baldwin, L. P. and Sabry, K. (2003) Learning styles for interactive learning systems, Innovations in Education and Teaching International, 40, 4, 325-340.

Barker, J. (2007) IG3: The Processes \& Technology, Course Module Material, ADU, UAE. 
Barker J.R., and Finnie G. (2004) A Model for Global Material Management using Dynamic Information. Proceedings of the Americas Conference on Information Systems, New York, USA, August 5-8, 2004, p4.

Barker, P. (1994) Designing interactive learning. In T. de Jong \& L. Sarti (Eds.) Design and Production of Multimedia and Simulation-based Learning Material. Kluwer Academic, Dordrecht, Netherlands.

Barker, P. (1997) Flexible Access to Learning Resources through Electronic Course Delivery. Available online: http://www.philip-barker.demon.co.uk/flexible97.htm (visited: Jul 08)

Barker, P. (2005) Knowledge Management for e-learning. Innovations in Education and Teaching International, 42, 2, 111-121.

BECTA (2007) Emerging technologies for learning. Volume2. Available online: http://partners.becta.org.uk/page_documents/research/emerging_technologies07_chapter2. pdf (visited: Jul 08)

Bonk, C. J. (1999) Breakout from learner issues. International Journal of Educational Telecommunication, 5, 4, 387-410.

Bower, G. H. and Winzenz, D. (1970) Comparison of associative learning strategies, Psychonomic Science, 20, 119-120.

Blurton, C. (1999) New Directions of ICT-Use in Education. Learning Without Frontiers, UNESCO. Available online: http://www.unesco.org/education/educprog/lwf/dl/edict.pdf (visited: Jan 08).

Bransford, J. (1999) How People Learn: Brain, Mind, Experience, and School. National Research Council, Washington DC.

EnGuage (2004) $21^{\text {st }}$ Century skills. North Central Regional Educational Laboratory. Available online: http://www.ncrel.org/engauge/skills/agelit.htm (visited: Jan 08)

Evans, C. Baldwin, L. P. and Sabry, K. (2002) Interactivity in information systems for web-based learning. Proceedings of the UKAIS 2002 Conference, Leeds, UK.

Glumbert (2008) Shift Happens. Available online: http://glumbert.com/media/shift2 (visited: Jan 08)

Graham, D. McNeil, J. and Pettiford, L. (2000) Untangled Web: Developing Teaching on the Internet, Pearson Education Ltd, England.

Hannafin, M. Land, S. and Oliver, K. (1999) Open learning environments: foundations, methods, and models. In Reigeluth C (ed) Instructional Design Theories and Models: A New Paradigm of Instructional Theory (Vol. II), Lawrence Erlbaum Associates, New Jersey, pp115-142.

Harasim, L. Hiltz, S. Teles, L. and Turoff, M. (1995) Learning network: a field guide to teaching and learning online, MIT Press, Cambridge, MA.

Horton, W. (2000) Designing web-based training. John Wiley, USA. 
Hsi, S. and Fait, H. (2005) RFID enhances visitors' museum experience at the Exploratorium. Communications of ACM, 48, 9, September 2005.

IWS -Internet World Stats (2007) Internet usage statistics. Available online: www.Internetworldstats.com/stats.htm, September 2007 (visited: Dec 07).

Jonassen, D. (1988) Instructional designs for microcomputer courseware. Lawrence Erlbaum Associates, Hillsdale, NJ.

Jung, I. and Leem, J. (1999) Training manual for the design of web-based instruction. Korea National Open University, Korea.

Jung, I. Lim, C. Choi, S. and Leem, J. (1998) Development of teaching-learning models foe WBI for lifelong education. Korea Foundation for Research, policy paper, Korea.

Klassen, J., Vogel, D. R. and Moody, E. (2001) Interactive learning: design and evaluation. Proceedings of the 34th Hawaii International Conference on System Sciences, January 03-06, Maui, Hawaii.

Laurillard, D. (1993) Rethinking university teaching: A framework for the effective use of educational technology, London, Routeledge.

Laurillard, D. (2002) Rethinking university teaching: a conversational framework for the effective use of educational technology. $\left(2^{\text {nd }} e d\right)$. RoutledgeFalmer, London, UK.

Lin, X. Hmelo, C. Kinzer, C. and Secules, T. (1999) Designing technology to support reflection. Educational Technology Research and Development, 47, 3, 43-62.

Lumsdaine, A. (1996) Educational technology programmed learning and instructional science. In Ely, D P and Plomp, T (eds) Classic Writing on Instructional Technology, Englewood Co, Libraries Unlimited, p79.

Mayer, R. (1989) Systematic thinking fostered by illustrations in scientific text. Journal of Educational Psychology, 81, 240-46.

Mayer, R. (2001) Multimedia learning. Cambridge University Press, UK.

Moore, M. (1989) Editorial: three types of interaction. The American Journal of Distance Education, 3, 2, 1-7.

Moore, M. and Kearsley, G. (1996) Distance education: A systems view. Belmont, CA.

Naidu, S. (1997) Collaborative reflective practice: An instructional design architecture for the Internet. Distance Education, 18, 2, 257-283.

Najjar, L. J. (1998) Principles of educational multimedia user interface design. Human Factors, 40, 2, 311-323.

Nelson, L. (1999) Collaborative problem solving. In Reigeluth C. (ed), Instructional Design Theories and Models, Volume II, pp244-269, Lawrence Erlbaum Associates, New Jersey.

ONS -Office of National Statistics (2007) Internet Access- Households and Individuals. Available online: http://www.statistics.gov.uk/pdfdir/inta0807.pdf (visited: Jan 08). 
Orlikowski, W.J. and Iacono, C. S. (2001) Desperately seeking the 'IT' in IT research: A call to theorizing the IT artefact. Information Systems Research, 12, 2, 121-134.

Park, C. (2003) Engaging Students in the Learning Process: the learning journal. Journal of Geography in Higher Education, 27, 2 183-199.

Paul, J. R. (1993) Why users cannot get what they want. ACM SIGIOS Bulletin, 14, 2, 812, December 1993.

Reeves, T. C. and Reeves, P. M. (1997) The effective dimensions of interactive learning on the WWW. In Khan B. (ed) Web-based instruction, Englewood Cliffs NJ, Educational Technology Publications.

Reeves, T. (1999) The Scope and Standards of the Journal of Interactive Learning Research. Available online: http://www.aace.org/pubs/jilr/scope.html (visited: Jan 08).

Sabry K. (2005) Interactive Learning Systems for Higher Education: Learning Styles and Students' Attitude. PhD Thesis, Brunel University, UK.

Sabry, K. and Al-Shawi, S. (2008) Information Systems for Interactive Learning: Design Perspective. Proceedings of European and Mediterranean Conference on Information Systems 2008, May 25-26 2008, Al Bustan Rotana Hotel, Dubai, UAE.

Salmon, G. (2002) E-tivities: The key to active online learning. Kogan Page, UK.

Street, S. and Goodman, A. (1998) Some Experimental Evidence on the Educational Value of Interactive Java Applets in Web-Based Tutorials. Available online: http://www.deakin.edu.au/ agoodman/publications/acse98.pdf (visited: Jan 08).

Tam, S. W. (2000) Managing learner-centredness: the role of effective student support in ODL. Proceedings of the ICDE Asian Regional Conference, New-Delhi.

Tessler, S., Iwasaki, Y. and Kincho Law, K. (1995) Qualitative structural analysis using diagrammatic reasoning. In Glasgow, J., Narayanan, N. and Ghandrasekeran, G. (eds) Diagrammatic Reasoning: Cognitive and Computational Perspectives, MIT Press, Cambridge, pp711-730.

Thijs, A., Almekinders, R., Blijleven, P., Pelgrum, W. J. and Voogt, J. (2001) Learning through the web: A literature study on the potential uses of the web for student learning. University of Twente, Enschede.

World Bank (1998) The World Development Report 1998/99. Quoted in Blurton, C., New Directions of ICT-Use in Education.

\section{BIOGRAPHICAL NOTE}

Dr Khaled Sabry is an Assistant Professor in the Department of Management Information Systems, Al-Ain University, UAE. His research interests in Dynamic and Interactive Information Systems and Learning Systems. Email: khal_sabry@yahoo.co.uk. 
Professor Jeff Barker is an Adjunct Professor at Bond University, Queensland, Australia, and Chairman and CEO of IG3 Research and Applications Pty Ltd. E-mail: jrb@bigpond.net.au

\section{LIST OF FIGURES}

Figure 1: Components of a Learning System (Adapted from Sabry, 2005)

Figure 2: Learning Interactions (diagram adapted from Sabry and Baldwin, 2003)

Figure 3: ILS Model (Source: Baldwin and Sabry, 2003)

Figure 4: New Pedagogy (Source: Thijs et al., 2001)

Figure 5: Dynamic Interactive Learning System Model (DILS)

Figure 6: DILS 5 types of Interaction 